\title{
Sapin Guy, Les villes atlantiques européennes, une comparaison entre l'Espagne et la France (1650-1850)
}

Presses universitaires de Rennes, 2019, 285 p.

Philippe Boulanger

\section{CpenEdition}

\section{Journals}

Édition électronique

URL : https://journals.openedition.org/geohist/1445

DOI : 10.4000/geohist. 1445

ISSN : 2264-2617

Éditeur

Association française de la Revue de géographie historique

Référence électronique

Philippe Boulanger, «Sapin Guy, Les villes atlantiques européennes, une comparaison entre l'Espagne et la France (1650-1850) », Revue de géographie historique [En ligne], Comptes-rendus, mis en ligne le 20 novembre 2019, consulté le 12 juin 2021. URL : http://journals.openedition.org/geohist/1445 ; DOI : https://doi.org/10.4000/geohist.1445

Ce document a été généré automatiquement le 12 juin 2021.

\section{(i) $\$$}

Ce(tte) œuvre est mise à disposition selon les termes de la Licence Creative Commons Attribution Pas d'Utilisation Commerciale - Pas de Modification 4.0 International. 


\section{Sapin Guy, Les villes atlantiques européennes, une comparaison entre l'Espagne et la France (1650-1850)}

Presses universitaires de Rennes, 2019, 285 p.

\section{Philippe Boulanger}

\section{RÉFÉRENCE}

Sapin Guy (sous la dir.), Les villes atlantiques européennes, une comparaison entre l'Espagne et la France (1650-1850), Presses universitaires de Rennes, 2019, 285 p.

1 Cet ouvrage collectif, dirigé par Guy Sapin (université de Nantes), s'inscrit dans la continuité de plusieurs travaux publiés sur ce thème par le même éditeur. Il vient compléter une somme de connaissances sur le concept de «ville atlantique européenne ». Il apporte aussi une nouvelle dimension scientifique au sujet tant par l'originalité de son approche géohistorique en comparant les situations française et espagnole que par la publication de nouvelles recherches et réflexions. Le concept de ville atlantique européenne renvoie à l'intégration des villes dans les échanges de l'espace atlantique, reliant les continents européen, africain et américain. Entre 1650 et 1850, l'Espagne et la France sont deux grandes puissances de l'Europe grâce à la mise en œuvre d'un vaste système d'accumulation des richesses. La période est marquée, somme toute, par l'apogée du premier système colonial de modèle mercantiliste, le développement des révoltes revendiquant les premières formes de décolonisation, la concurrence croissante du commerce anglo-saxon (Angleterre/Etats-Unis), les transformations sociales des sociétés urbaines liées à cette dynamique économique et géopolitique. Les dix-sept contributions abordent cette orientation scientifique par le biais de l'espace urbain et de l'urbanisme valorisant ainsi une approche en géographie historique. 
2 Pour Guy Sapin, «la ville est analysée comme un point nodal de toutes les circulations qui structurent le monde atlantique, en tant que produit de la symbiose entre ce qui lui vient de son hinterland, de son appartenance nationale et de la somme de ses relations atlantiques à toutes les échelles identifiables ». Le raisonnement est fondé sur la spatialisation des processus tout en conservant une dimension historique pour aborder cette évolution de redistribution des dynamiques urbaines et sociales. Après une introduction présentant les enjeux historiques et géopolitiques des deux Royaumes, l'ouvrage s'articule en trois grandes parties de manière équilibrée : dynamiques atlantiques et évolution des villes portuaires, dynamiques atlantiques et transformations des sociétés urbaines portuaires, dynamiques atlantiques et morphologie urbaine des villes portuaires.

Ces trois parties contribuent à comprendre la dynamique de transformation de la hiérarchie portuaire en valorisant une approche comparative entre les villes. Les auteurs analysent les spécificités des villes atlantiques européennes qui se distinguent des villes de l'intérieur et de celles des Amériques. Celles-ci se caractérisent par leur développement comme centres attractifs commerciaux ou comme bases navales comme Donastia-San Sébastian, Ferrol, Nantes, Bordeaux, Avilés, Gijón, Santander, La Rochelle, Cadix ou les arsenaux entre autres exemples. Elles révèlent aussi leur connexion à un vaste réseau d'échanges où l'activité entrepreneuriale privée prend le pas sur le système du monopole de plus en plus contesté. Enfin, cet essor d'activités économiques et militaires participe à remodeler l'espace urbain, à créer des villes nouvelles et à les embellir grâce à une nouvelle élite de négociants au siècle des Lumières. Tous ces éléments conduisent à faire émerger une nouvelle forme d'attractivité spatiale que renforcent les mobilités socio-culturelles et leur cosmopolitisme. Malgré un appareil cartographique parcimonieux, force est de constater la qualité scientifique des analyses sur l'essor des villes atlantiques européennes entre 1650 et 1850 qui en fait un ouvrage incontournable sur le sujet. 